Consanguinity and family history were positive in almost all of the cases. For means of diagnosis, referral was done for aminoacid profile. outcome of the cases varied from early neonatal death to normalcy through later childhood.

Conclusion and recommendations The high consanguinity rate in our country makes IEM not uncommon problem. Estimation the overall incidence of IEM in general and UCD in particular is needed. Further studies are needed to explain the higher incidence in Northern Gaza. Lack of metabolic specialist and metabolic laboratory necessitates referral of cases which has many problematic issues. We need to have metabolic specialist and genetist as well as our own metabolic and genetic lab in Gaza strip.

\section{DETERMINATION OF THE PERFUSION INDEX REFERENCE VALUES AND VARIATION IN CLINICALLY AND HEMODINAMICALLY STABLE NEWBORNS DURING THE EARLY NEONATAL PERIOD}

doi:10.1136/archdischild-2012-302724.1039

N Hakan, D Dilli, A Zenciroğ lu, N Okumuş, BS Karagöl, A Dursun, N Karadağ, S Beken, B Aydın, S Erol. Dr Sami Ulus Maternity, Childrens Education and Research Hospital, Division of Neonatology, Ankara, Turkey

Background and Aims The perfusion index (PI); is an easy, noninvasive technique for the assessment of peripheral perfusion. The aim of this study was to determine the peripheral PI reference values and PI variability of clinically and hemodynamically stable newborns during the first five days.

Method Pre- (right hand) and postductal (foot) PI values were recorded on the sixth hours, first, second, third and fifth day of 241 newborns life with the new generation pulse oximeter [MASIMO Rad 7 Oximeter, USA]

Results A total of 241 newborns (196 term, 45 preterm) were included in the study. The average gestation age of all newborns was $38.4 \pm 2.0$ weeks and birth weight was $3204 \pm 566$ grams. According to the analysis of repeated measurements of term and preterm groups within the first 5 days, PI values of right hand and foot did not vary. However, right hand PI values were significantly higher than foot PI values $(\mathrm{p}<0.001)$. During the first 3 days, both the right hand and foot PI median values of term newborns were significantly higher than preterm newborns $(p<0.001)$ whereas on the fifth day, difference was disappeared (right hand; $\mathrm{p}=0.10$, foot; $\mathrm{p}=0.45$ ).

Conclusion The peripheral perfusion of stable newborns did not vary significantly during the first five days. It was considered, higher PI value of term newborns compared to preterm newborns, is the result of early adaptation in the microvascular blood flow. PI values obtained from stable newborns may be guiding for further studies planned on various diseases associated with impaired perfusion.

\section{EVALUATION OF THREE RESUSCITATION PROTOCOLS IN HYPOVOLEMIC SHOCK USING MICROCIRCULATION ANALYSIS IN AN ANIMAL MODEL}

doi:10.1136/archdischild-2012-302724.1040

1,2R Gonzalez, 'J Urbano, 1,2MJ Solana, 'M Botran, 'A García, 'J López-Herce, 'J López. 'Pediatric Intensive Care, Gregorio Marañón General University Hospital and Research Institute; ${ }^{2}$ Health Research Found, Health Institute "Carlos III", Madrid, Spain

Background and Aims Ideal treatment of hypovolemic shock is not well established yet. Comparison of different treatments usually focuses on global haemodynamics. Our aim was to study if microcirculation analysis shows differences between three different resuscitation treatments.

Methods After sedation, relaxation and mechanical ventilation, hypovolemic shock was induced with controlled bleed $(30 \mathrm{ml} / \mathrm{kg})$ in 17 two-month-old piglets. After 30 minutes pigs randomly received treatment with either normal saline (NS) $30 \mathrm{ml} / \mathrm{kg}$, Albumin 5\% plus Hypertonic 3\% Saline (AHS) $15 \mathrm{ml} / \mathrm{kg}$ or Albumin $5 \%$ plus Hypertonic 3\% Saline plus a bolus of Terlipressin $20 \mu \mathrm{g} / \mathrm{kg}$ (TAHS). Microcirculation was assessed following international consensus recommendations. Perfused vessel density (PVD), microvascular flow index (MFI) and heterogeneity index (HI) where determined at basal, post bleeding and after treatment.

Results After treatment PVD and MFI where higher in AHS and TAHS groups than NS group and HI values were lower, but differences between the three treatment groups were not statistically significant. Median values for PVD were 13.0 \pm 0.9 (NS); $14.0 \pm 1.8$ (AHS) and 14.0 \pm 1.9 (TAHS) ( $\mathrm{p}=0,539)$. MFI median values were $2.47 \pm 0.29$ (NS); $2.75 \pm 0.23$ (AHS) and 2.67 \pm 0.19 (TAHS) $(\mathrm{p}=0,204)$. HI median values were $0.43 \pm 0.23$ (NS); $0.22 \pm 0.20$ (AHS) and $0.32 \pm 0.21$ (TAHS) $(p=0,316)$

Conclusions After treatment there were no significant differences between the three treatments in none of the three microcirculation parameters. There are no significant differences in microcirculation analysis between several treatments of hypovolemic shock.

\section{PERFUSION INDEX ASSESSMENT IN NEWBORNS WITH TACHYPNEA}

doi:10.1136/archdischild-2012-302724.1041

S Unal, N Altuntas, S Beken, F Kulalı, E Kazancı, IM Hirfanoğlu, C Türkyılmaz, EE Önal, E Koç, Y Atalay, E Ergenekon. Neonatology, Gazi University Hospital, Ankara, Turkey

Background and Aim Tachypnea of newborn is a frequent respiratory problem which may be due to several causes. Perfusion index (PI) is a way of monitoring of peripheral perfusion noninvasively. The aim of this study was to compare PI of newborns with and without tachypnea within the 1 st hour of life.

Methods Neonates born at gestational age $>36$ weeks with C/S were monitored with Masimo Set Radical 7 pulse-oximeter postductally. PI and oxygen saturation ( $\mathrm{SaO} 2)$ values, respiratory rates $(\mathrm{RR})$, temperature and heart rate were manually recorded every ten seconds during first 3 minutes after the newborn was taken to the transition area (baseline) and at the 60 minutes of life.

Results Study included 30 tachypneic neonates 7 of which were admitted for transient tacypnea of newborn (TTNB) and 24 neonates with normal respiratory rates (controls). Birth weight of 30 tachypneic newborns were higher than controls $\mathrm{p}<0.01$ whereas GA were similar. None of the neonates had risk for sepsis and all had capillary refill time $<3 \mathrm{sec}$. PI values were similar between groups both at baseline and at 1 hour (median and range; controls: 1.52(0.68-3.05), tachypnea:1.38 (0.68-3.07), TTNB: $1.2(1.02-1.60)$ at baseline and controls: $1.23(0.66-2.84)$, tachypnea: $1.42(0.65$ 3.40), TTNB: $1.22(1.03-2.08)$ at 1 hour. Only RR values were significantly different between groups.

Conclusion Low PI may be associated with various pathological conditions. The results of this study suggests that if the newborn has only transient tachypnea the PI remains normal which might be helpful for the clinician to decide about management.

\section{INCREASED PLASMA AND URINE NITRIC OXIDE LEVEL IN INTRAUTERINE GROWTH RESTRICTED LATE PRETERM INFANTS}

doi:10.1136/archdischild-2012-302724.1042

'S Huseynova, 'S Alasgarova, 'S Mukhtarova, 'S Ali-Zade. 'Neonatology, Azerbaijan Medical University; ${ }^{2}$ Pediatry, Odlar Yurdu, Baku, Azerbaijan

Background and Aims Nitric oxide (NO) is a vasodilator produced from different groups of nitric oxide synthases and plays an important role in regulation of vascular tone and blood flow in different organs. The aim of this study is to determine the connection 
between intrauterine growth inhibition and $\mathrm{NO}$ activity in late preterm infants.

Methods Newborns with gestational age of 34-36 weeks and birth weight of 1200-2600 g were allocated to two groups: 21 infants with normal growth parameters were classified as first group and 15 intrauterine growth restricted (IUGR) infants were included in second group. Gestational age was assessed by the last menstrual period and confirmed by scale of Ballard et al. Plasma and urine samples of infants were collected on the first day of life. Nitric oxide concentration quantified by principle based on using the enzyme Nitrate Reductase to convert nitrate to nitrite.

Results Mean plasma nitrat products were higher $(\mathrm{p}<0.05)$ in second group infants $(42.6 \pm 7.3 \mu \mathrm{M} / \mathrm{L})$, than in first group (59 \pm 7.3 $\mu \mathrm{M} / \mathrm{L})$. Statistically true rising $(\mathrm{p}<0.01)$ was noted in urine NO level of IUGR infants, where mean NO level was 1.4 times higher compared with first group newborns.

Conclusion Intrauterine growth retardation is associated with high NO production of infants at an early neonatal period, which might indicate intrauterine activation of NO sources of fetus.

\section{EVALUATION OF PEDIATRIC TESTES AFTER SURGERY BY LASER DOPPLER AND WHITE LIGHT SPECTROSCOPY}

doi:10.1136/archdischild-2012-302724.1043

${ }^{1} \mathrm{~J}$ de Laffolie, ${ }^{2} \mathrm{R}$ Freudenberger, ${ }^{2} \mathrm{~S}$ Turial, ${ }^{2} \mathrm{~V}$ Engel, ${ }^{2} \mathrm{~F}$ Schier. ${ }^{1}$ General Pediatrics and Neonatology, University of Gießen, Giessen; 2Department of Pediatric Surgery, University of Mainz, Mainz, Germany

Aim To evaluate testes after unilateral orchiopexy Laser Doppler and white light spectroscopy and compare microcirculation with contralaterat testis and healthy controls.

Methods A combination of the laser Doppler (determination of blood flow) and white light spectroscopy (determination of oxygen saturation and hemoglobin amount) is used to determine microcirculation at two different depth levels non-invasively. Patients were recruited after unilateral orchiopexy. Controls were age-matched boys without relevant disease. Ethical approval was obtained.

Results 99 patients were included after unilateral orchiopexy at the age of 3.5 years (+-2.9 years). $65 \%$ underwent surgery after their second birthday. Follow-up was at median 2.5 years after surgery (3months - 10.5 years). Controls were 29 boys at the age of median 6.3 years ( 3 month-13 years). There was no significant difference in age between both groups.

85 patients were examined on the operated side with laser doppler and white light spectroscopy. Significant higher flow and velocity were found contralateral ( $\mathrm{p}=0.041, \mathrm{p}=0.022)$. Surprisingly, when comparing the contralateral testes in patients after orchiopexy with healthy controls, flow and velocity were significantly higher in the healthy controls $(p<0.001)$, even though this testis was previously not operated on.

Conclusion After orchiopexy, expected differences were found in microcirculation between the operated and contralateral testes or healthy controls. Surprisingly, the contralateral testes' microcirculation was also significantly different from controls. This is probably not a consequence of surgery alone, but more likely a common problem of both testes in the affected patients.

\section{EVALUATING MODE OF DELIVERY OF IRON OR IRON AND ZINC ON IRON STATUS AND IRON STRESS MARKERS}

doi:10.1136/archdischild-2012-302724.1044

${ }^{1} \mathrm{U}$ Dhingra, ${ }^{2} \mathrm{~A}$ Pradhan, ${ }^{3} \mathrm{VP}$ Menon, ${ }^{1} \mathrm{~A}$ Dutta, ${ }^{4} \mathrm{P}$ Dhingra, ${ }^{1} \mathrm{R}$ Black, ${ }^{4} \mathrm{~S}$ Madhesiya, ${ }^{4} S$ Gupta, 'S Sazawal. 'International Health, Johns Hopkins Bloomberg School of Public Health, Baltimore, MD, USA; ${ }^{2} R H N$, Indian Council of Medical Research, New Delhi; ${ }^{3}$ Center for Micronutrient Research, Clinical Trials and Operational Research in Maternal and Child Health (CMR-CTORMCH), Annamalai; ${ }^{4}$ Center for Public Health Kinetics, New Delhi, India
Background Iron deficiency remains a major nutritional problem among infants and young children in India. The tablet/syrup-based programs do have logistic, supply and compliance challenges. Tablet/Syrup may have increased risk of free iron in blood, oxidative stress and risk of infections.

Objective In a community based RCT we evaluated 3 approaches of iron delivery for impact on iron status, pro and anti-inflammatory interleukins and non-transferrin bound iron (NTBI) with 30 day intervention

Methods 300 children 22-34 months were enrolled and randomized to receive either iron fortified biscuit $(n=74)$, iron tablet $(n=77)$, iron+ zinc tablet $(\mathrm{n}=74)$ or placebo $(\mathrm{n}=75)$ for 30 days.

Results Delivery of iron through biscuit showed better impact on hemoglobin (Mean Diff: 0.60; $95 \%$ CI: 0.16-1.04) and other hematological markers like RDW, MCV and $\mathrm{MCH}$ at 30 day post supplementation. The NTBI estimation at day 1 and 30 post supplementation, 3 hours after ingestion of supplement dose; an indicator of oxidative stress caused by dose after iron status repletion, suggested the lowest burden with biscuit $(2 \%)$ and a higher burden with supplements (6-7\%). At day 30 there was no effect on interleukins in the biscuit group; increase in IL-6/IL10 in iron tablet, increase in IL-8/ IL10 in iron+zinc tablet group.

Conclusion Providing iron through fortified biscuits was as efficient and effective in improvement of iron status and hematological markers as iron tablets. Biscuit was marginally better for NTBI or immune response. The benefit of using biscuits needs to be evaluated in a larger community based effectiveness program.

\section{LONGITUDINAL STUDIES OF BREAST MILK ZINC TRANSFER TO APPROPRIATE- AND SMALL-FOR-GESTATIONAL-AGE, PREDOMINANTLY BREAST FED, BANGLADESHI INFANTS}

doi:10.1136/archdischild-2012-302724.1045

MM Islam. Centre for Nutrition and Food Security, ICDDR, B, Dhaka, Bangladesh

Background In developing countries, information is limited on concentration of breastmilk zinc, total amount of zinc transferred to infants through breast milk and whether zinc transfer through breastmilk differs among appropriate-for-gestational-age (AGA) and smallfor-gestational-age (SGA) infants at different times post-partum.

Aims To measure breastmilk and zinc transfer through breastmilk, using deuterium "dose-to-mother" technique, in mothers of AGA and SGA infants.

Methods Forty-six mother-infant pairs were recruited (20 AGA and 26 SGA infants). Each mother-infant pair was studied three times, at 4, 12 and 24 weeks post-partum. In each round, two-week studies of breast milk transfer were carried out, using the deuterium oxide "dose-to-mother" technique. Breast milk samples were collected on days 1 and 5 of each round for milk zinc concentration.

Results Mean $( \pm S D)$ birth weight and length were $3.02 \pm 0.2 \mathrm{~kg}$ and $48.2 \pm 1.2 \mathrm{~cm}$ for AGA infants and $2.34 \pm 0.20 \mathrm{~kg}$ and $46.2 \pm 1.1 \mathrm{~cm}$ for SGA infants. Breast milk intake increased gradually with time postpartum, and was marginally greater among AGA infants only at 4 weeks $(p=0.06)$. Breast milk zinc concentration decreased when the infants grow $(p<0.001)$, but differed between neither of the groups. Zinc transfer through breast milk decreased significantly with age in both the groups, but did not differ $(p<0.001)$.

Conclusions Breast milk zinc concentration among Bangladeshi mothers was similar to values reported for women from wealthier countries, and there was no relationship between infant birth weight category and milk zinc concentration or milk zinc transfer.

\section{IODINE STATUS IN PRESCHOOL CHILDREN AND EVALUATION OF MAJOR DIETARY IODINE SOURCES: A} GERMAN EXPERIENCE

doi:10.1136/archdischild-2012-302724.1046 